\title{
The Role of Nutrition in Health and Wellness
}

\author{
Dr. Ben Ohuruogu \\ Ebonyi State University \\ Alor Roseline Chinyere. \\ Ebonyi State College of Education, Ikwo \\ Barr Njoku B. O. \\ Ebonyi State University
}

\begin{abstract}
This paper x-rays the major role nutrition plays in human lives from birth through to death, the satisfaction of nutrition needs as being mandatory to human life from conception throw growth and development and, the achievement of long term survival. The paper also sees nutrition as a balance of the three basic food types such as carbohydrates, fats and protein vitamins and minerals. It also sees nutrition playing a key role in the realization of the "sustainable development goal" as adequate nutrition in enough quantity and quantity offer a better cost benefit ratio than trade liberation, reduction in migration barriers, new agriculture technologies, climate charge and sanitation. Poor nutrition can impair our daily health and wellbeing and reduce our ability to live an enjoyable and active life. The paper concluded by stating that nutritional deficiencies contributes to the high rate of disability, morbidity and mortality especially among infants and young children.
\end{abstract}

Keywords: Nutrition, health, wellness, food, survival

DOI: $10.7176 / \mathrm{JNSR} / 9-24-06$

Publication date: December $31^{\text {st }} 2019$

\section{Introduction}

Nutrition plays a major role in the human life cycle from birth to death beginning with fertilization through the stages of growth, development and aging. The role of Nutrition, which can modify the genetic base is of crucial importance in the life cycle. Life maintenance requires food as well as water and oxygen. Food provides the energy required to support the body life sustaining process and the materials required to build and maintain all body cells. These materials, called nutrients, undergo extremely complex process in the body, cells and tissues to maintain the overall health of the individual.

The satisfaction of nutritional needs is mandatory to human life from conception through growth and development and finally to the achievement of long-term survival. Diet is a major influence during the human life cycle since food preferences, influenced by likes and dislikes; mainly determine what people eat. In order to achieve maximum genetic potential in the human life cycle, optimal nutritional needs must be satisfied. Eating a good diet can help provide the energy you need to finish a race, or enjoy a causal sport or activity. You are merely to be tired and perform poorly during sports when one does not have enough of calories, carbohydrates, fluids, iron, vitamins and other minerals as well as protein.

Nutrition, health and wellness are intricately inter-linked, as nutrition influence significantly on our health and well-being. What one eats has a profound effect on our overall wellness thus, adequate nutrition is essential to growth and development. The period from conception to age two is especially important from optional physical, mental, cognitive growth, health and development. However, this period is often marked by protein - energy and Micro nutrient deficiencies that interfere with optimal growth. A woman, nutritional status has important implications for her health as well as for the health of her children. Malnutrition results in reduced productivity, increased susceptibility to infections, slow recovery from illness and a heightened risk of adverse pregnancy outcomes. For example, a woman with poor nutritional status, as well as indicated by a low body mass index (BMI), short stature, anaemia, or other micronutrient deficiencies, has a greater risk of obstructed labour, having a baby with a low birth weight, producing low-quality breast milk or death due to postpartum haemorrhage, and morbidity for herself and her baby. In other words, poor health can be caused by a lack of required nutrients or, in extreme cases too much of a required nutrients. 
Nutrition refers to the food (nutrients) that we eat. Proper nutrition requires a balance of the three basic food types - carbohydrates, fats and proteins, plus essential vitamins and minerals.

Health maintenances is a systematic programme or procedure planned to prevent illness, maintain maximum function and promote health and wellness.

\section{Health}

Larson (1999) states that the World Health Organization (WHO, 1948) was the first to introduce a holistic definition of health as "a state of complete physical, mental, and social well-being and not merely the absence of disease and infirmity", and many subsequent conceptualizations of wellness include this central concept.

\section{Wellness}

Oliphant (2001) explains that the suggestion by WHO (1967) that health has a positive component led to the now widely used term "Wellness". Which means positive state that is beyond simply non-sickness. Dunn (1977) saw wellness as a positive state, one that is beyond simply non-sickness, elaborating on the WHO definition by emphasizing the varying degrees of wellness and its interrelationship, ever-changing aspects.

Myers, Sweeney, and Wittmer (2005) define wellness as "a way of life oriented toward optimal health and well-being in which the body, mind, and spirit are integrated by the individual to live more fully within the human and natural community." The notion that wellness is more a psychological than a physical state has been a focus of several researchers. Anspaugh and co-authors (2004), and Hales (2005) refer to seven dimensions of wellness: physical, emotional, social, intellectual, spiritual, environmental, and occupational.

Jonas (2005) elaborates on the difference between health and wellness, saying that health is a state of being, whereas wellness is a process of being. Wellness is defined as: a way of life and living in which one is always exploring, searching, finding new questions and discovering new answers, along the three primary dimensions of living: the physical, the mental, and the social; a way of life designed to enable each of us to achieve, in each of the dimensions, our maximum potential is realistically and rationally feasible for us at any given time in our lives. Rickhi and Aung (2006) believes that creating wellness can mean focusing on practices that benefit one or all of the three dimensionsbody, mind, and spirit.

Physical wellness includes drinking water, healthy eating, healthful touch such as massage and physical activity. Mental and spiritual wellness requires mind/body-based on stress reduction programs, adapting the body to nature and being aware of the senses. While Ajala (2003) viewed wellness as any approach to health that focuses on balancing the many aspects or dimensions, of a person's life through increasing the adoption of health enhancing condition and behaviour rather than attempting to minimize conditions of illness.

\section{Main principles of wellness}

The following are principles of wellness (Adams, 2003):

1) Wellness is multi- dimensional;

2) Wellness research and practice should be oriented toward identifying causes of wellness rather than causes of illness;

3) Wellness is about balance; and

4) Wellness is relative, subjective, and perceptual.

Schuster and colleagues (2004) states that there is general consensus that the definitions of health should include multiple domains, among them physical, psychological (mental, intellectual, emotional), social, and spiritual. Wellness is described as "a higher order construct integrating these domains, drawing on individual selfperception."

\section{Dimensions of Wellness}

From the foregoing, there are several main dimensions to defining wellness: physical; psychological/emotional; social; intellectual; spiritual; occupational; and environmental. 


\section{Physical Wellness}

In general, physical wellness includes physical activity, nutrition, and self-care, and involves preventive and proactive actions that take care of one's physical body. (Cooper 1968, 1970, 1975 and 1977) studied the relationship of exercise to health and longevity, particularly how exercise reduced the risk of heart disease. His findings revolutionized the fitness industry's understanding of health and wellness and advanced the understanding of the relationship between living habits and health.

Physical wellness encompasses maintenance of cardiovascular fitness, flexibility, and strength. Actions to improve physical wellness include maintaining a healthy diet and becoming in tune with how the body responds to various events, stress, and feelings by monitoring internal and external physical signs.

\section{Psychological/Emotional Wellness}

Emotional wellness is seen as awareness and control of feelings, as well as a realistic, positive, and developmental view of the self, conflict, and life circumstances, coping with stress, and the maintenance of fulfilling relationships with others (Adams, Bezner, and Steinhardt, 1997; Leafgren, 1990). Hettler (1980) considered emotional wellness to be a continual process that included awareness and management of feelings, and a positive view of self, the world, and relationships.

Renger and co-workers (2000) defined emotional wellness as related to one's level of depression, anxiety, well-being, self-control, and optimism. Emotional wellness includes experiencing satisfaction, curiosity, and enjoyment in life, as well as having a positive anticipation of the future, or optimistic outlook.

\section{Social Wellness}

Social wellness encompasses the degree and quality of interactions with others, the community, and nature. It includes the extent to which a person works toward supporting the community and environment in everyday actions, such as volunteer work (Hettler, 1980). Social wellness also deals with getting along with others and being comfortable and willing to express one's feelings, needs, and opinions; supportive, fulfilling relationships (including sexual relations), and intimacy; and interaction with the social environment and contribution to one's community.

Durlak (2000) includes peer acceptance, attachments/bonds with others, and social skills (communication, assertiveness, conflict resolution) as fundamental to social wellness. Helliwell (2005) found that married people are happier, and separated individuals are the least happy, even less so than those who are divorced.

\section{Intellectual Wellness}

Intellectual wellness is the degree to which one engages in creative and stimulating activities, as well as the use of resources to expand knowledge and focus on the acquisition, development, application, and articulation of critical thinking. It represents a commitment to lifelong learning, an effort to share knowledge with others, and development of skills and abilities to achieve a more satisfying life (Hettler, 1980).

Renger and co-authors (2000) also defined intellectual wellness as one's orientation and attitude toward personal growth, education, achievement, and creativity. This includes attending cultural events and seeking out opportunities to gain and share knowledge, particularly knowledge of current local and world events. In addition to attending cultural events (Leafgren 1990) cites that stimulation can come from reading, studying, travelling, and exposure to media, Durlak (2000) includes the development of talents and abilities, learning how to learn, and higher order thinking skills in intellectual wellness.

\section{Spiritual Wellness}

Spiritual wellness is possibly the most developed and discussed topic in the wellness literature (Banks, 1980; Hatch, Burg, Naberhaus, and Hellmich, 1998; Ingersoll, 1994; Pargament, 1999). Spirituality is not synonymous with religion (Adams, 1997). Rather, religiosity and spirituality are overlapping but distinct concepts (Westgate, 1996). Spirituality can be considered to be the broader concepts of beliefs and values, whereas religiosity can be thought of as behaviours and the means of implementing one's spirituality (Westgate, 1996; Hatch et al., 1998), although Pargament (1999) has challenged this viewpoint and argued that religiosity is the broader concept.

Hettler (1980) and others (Adams, 1997; Renger, 2000) defined spiritual wellness as the process of seeking meaning and purpose in existence. It includes the appreciation of the depth and expanse of life and the universe, questioning the meaning and purpose in life, as well as recognizing, accepting, and tolerating the complex nature of the world and accepting that the universe cannot be completely understood. 
Other important elements include; a commitment to God or ultimate being, perception of what it is that makes the universe operate as it does, recognition of powers beyond the natural and rational, a matter of faith in the unknown, involving a survival issue, and finally a pleasure-producing quality of humans.

Westgate (1996) defined spiritual wellness in terms of holistic dimensions, proposing four spiritual wellness dimensions: meaning in life, intrinsic values, transcendence, and spiritual community. The meaning in life dimension was described as an innate human need where purpose and life satisfaction provide hope. Intrinsic values were defined as the basis of human behaviour and the principles that people live by. Transcendence signifies a relationship with a higher force and the universe, recognition of the sacredness of life, and motivation by truth, beauty and unity. Lastly, the fourth dimension of spiritual community was defined as giving and sharing with others, shared values, myths and symbols, and the experience of community and mutual support through gathering, singing, praying, and chanting.

\section{Occupational Wellness}

Anspaugh and colleagues (2004) defined occupational wellness as the level of satisfaction and enrichment gained by one's work and the extent one's occupation allows for the expression of values.

Furthermore, occupational wellness included the contribution of one's unique skills and talents to the community in rewarding, meaningful ways through paid and unpaid work. Lastly, occupational wellness incorporated the balance between occupational and other commitments.

Crose and co-workers (1992) sees occupational wellness to include work history, patterns and balance between vocational and leisure activities and vocational goals.

\section{Environmental Wellness}

Renger and co-authors (2000) include the balance between home and work life, as well as the individual's relationship with nature and community resources (i.e., involvement in a recycling or community clean-up effort). Anspaugh and colleagues (2004) and Hales (2005) further express concerns such as safety of food and water supply, infectious diseases, violence in society, ultraviolet radiation, air and water pollution, and second-hand tobacco smoke.

Ryff and Singer (2006) describe environmental mastery as a dimension of wellness and state that, to make the most of our lives and our world, we need to advance the science of interpersonal flourishing.

\section{Nutrition, Wellness and Health}

Nutrition is the science that interprets the interaction of nutrients and other substances in food (e.g. phytonutrients, anthocyanins, tannins, etc.) in relation to maintenance, growth, reproduction, health and disease of an organism. The concept of balanced diet to an average person is the consumption of palatable food which builds the body irrespective of the nutrients contained in this diet. It includes food intake, absorption, assimilation, biosynthesis, catabolism and excretion (WHO, 2012). Nutrition plays a key role in the realization of the 'Sustainable Development Goals' and adequate nutrition in enough quantity and quality offers a better cost benefit ratio than trade liberalization, reduction in migration barriers, new agriculture technologies, climate change and sanitation. Poor eating habits include under- or over-eating, not having enough of the healthy foods we need each day, or consuming too many types of food and drink, which are low in fibre or high in fat, salt and/or sugar. These unhealthy eating habits can affect our nutrient intake, including energy (or kilojoules) protein, carbohydrates, essential fatty acids, vitamins and minerals as well as fibre and fluid.

Therefore, the increase needs for certain nutrients for wellness and health might require supplementations. The five classes of food that influence wellness and health are:

- Carbohydrate,

- Protein,

- $\quad$ Fats \& oil,

- Mineral salts

- Vitamins as well as water are very vital for the wellbeing health.

\section{Carbohydrates}

There are two forms of carbohydrates - starchy or complex, and simple sugars. Simple sugars are carbohydrates which are found in refined sugars and provide a sweet taste while complex carbohydrates are also known as starches. 
Carbohydrate, Provides energy for the body functions and energy is measured in calories. A pregnant woman needs about 300-400 calories of energy in addition to the usual daily carbohydrate intake. Source of carbohydrate foods include monosaccharide (e.g. sucrose, glucose, fructose and lactose), disaccharide e.g. soft drinks \& domestic sugar. Complex polysaccharide e.g. whole grain, cereals, flour, bread, rice, yam, cassava, oats, legumes, potatoes etc.

\section{Protein}

Is present in every cell of the body and is important for helping to build and repair tissues. It helps in the structure of red blood cells for proper function of antibodies and most importantly, ensures the regulation of enzymes and hormones and a variety of additional body chemicals as well as forming the building blocks of bores, muscles, cartilage skin and blood.

High protein diet have also become a popular weight loss method, with some research suggesting that protein has the ability to satisfy hunger for a longer periods of time than fats and carbohydrates. Many individuals are attracted to the prospect of significant weight loss, which occurs as a muscle glycogen depletion.

Source: Animals and plants. Source of plant protein: legumes, beans, peanuts, Bambara nut etc.

\section{Vitamins and Mineral Salts}

Every human being needs to eat variety of these to maintain a good health. There are some important vitamins and minerals that are essentially important, especially in pregnancy. These include: folic acid, vitamin $\mathrm{C}$, calcium and iron. It is best to get vitamins from the food we eat but when you are pregnant you will need to take some supplements as well. It is an essential component of any diet as it helps the body to absorb nutrients as well as being a great source of energy which provides the body with essential fatty acids that it is unable to manufacture independently.

Folic Acid- Folic acid is important especially during pregnancy. Daily dose of 400 microgram of folic acid is recommended for every pregnant and lactating mother. Folic acid helps in preventing birth defects known as neural tube defects - This defect can cause spinal bifida. The source of folic acid in food include: green leafy vegetables, brown rice, cereals, breads and margarine. Baby born with neural tube defects as well as women with increased risk of having baby with neural tube defects take higher dose of 5 milligrams of folic acid daily. Higher dose of folic acid is also recommended for mothers who are diabetics and mothers taking medication for leprosy.

\section{Iron, Vitamin and Calcium}

There is need for optimal consumption of iron, vitamin and calcium for wellness and good health. Pregnant mothers will need increase iron intake to prevent anaemia and exhaustion over little exercise. Source: lean meat, green leafy vegetables, dried fruits, nuts and peanuts etc.

Vitamin $\mathrm{C}$ helps to absorb iron from the food. Citric acid, fruits, tomatoes, black current, potatoes, oranges, mangoes etc are the sources. Calcium strengthens the bone and teeth. Source -from dairy products - milk, fish with edible bones such as sardine, dried fruits, green leafy vegetable are all rich in calcium.

\section{Fluid and Water}

Adequate fluid intake help in preventing and treating constipation. It is recommended that everybody takes about 6-8 cups of water daily. The best guide to see if one has sufficient fluid is to look at your urine - clear or light yellow urine indicates proper hydration in the absence of any medical condition. Generally, the best fluid to choose is water, reduced or low fat milk and diluted fruit juice. Drinks like soft drinks or malt are high in sugar and offer little in terms way of nutrient.

\section{Benefits of Nutrition to Wellness and Health}

1. Some foods called functional foods provides benefits beyond nutrition but tends to provide health and wellness benefits and plays specific roles in reducing risk of certain diseases and other ill health conditions. Some examples and roles of such foods in disease prevention include; garlic for prevention of blood pressure, Soy bean reduces risk of breast cancer in women, tomatoes prevent prostrate cancer, nuts reduce risk of Coronary Heart Diseases (CHD), etc.

2. Controls weight: Eating right and exercising regularly can help you avoid excess weight gain and maintain a healthy weight. According to the Mayo Clinic, being physically active is essential to reaching your weightloss goals. Even if you're not trying to lose weight, regular exercise can improve cardiovascular health, boost your immune system, and increase your energy level. Eating a balanced, calorie-managed diet can also help 
control weight. When you start the day with a healthy breakfast, you avoid becoming overly hungry later, which could send you running to get fast food before lunch.

Additionally, skipping breakfast can raise your blood sugar, which increases fat storage. Incorporate at least five servings of fruits and vegetables into your diet per day. These foods, which are low in calories and high in nutrients, help with weight control. Limit consumption of sugary beverages, such as sodas and fruit juices, and choose lean meats like fish and turkey.

\section{Improves mood}

Good nutrition with simply physical activities stimulates the production of endorphins. Endorphins are brain chemicals that leave you feeling happier and more relaxed. Eating a healthy diet as well as exercising can lead to a better physique. You'll feel better about your appearance, which can boost your confidence and self-esteem. Short-term benefits of exercise include decreased stress and improved cognitive function.

\section{Combat diseases}

Healthy eating help prevent certain health conditions, such as heart disease, stroke, and high blood pressure. If you take care of yourself, you can keep your cholesterol and blood pressure within a safe range. This keeps your blood flowing smoothly and decreasing your risk of cardiovascular diseases.

Regular physical activity and proper diet can also prevent or help you manage a wide range of health problems, such as:

- metabolic syndrome

- diabetes

- depression

- $\quad$ certain types of cancer

- $\quad$ arthritis

\section{Boosts energy} diet includes:

When you eat an adequate diet your body receives the fuel it needs to manage your energy level. A healthy

- whole grains

- lean meats

- low-fat dairy products

- $\quad$ fruit

- $\quad$ vegetables

\section{Implication of Poor Nutrition to Wellness and Health}

Poor nutrition can impair our daily health and wellbeing and reduce our ability to lead an enjoyable and active life.

1. A chronic state of under nutrition in the adult has its cost in terms of risk to health and impairment of function, which may include a lowered work capacity, a reduced ability to sustain economically productive work or even socially desirable physical activities and possibly an impaired immune function with a predisposition to repeated infections (Food and Agricultural Organizaation, 1994).

2. Inadequate nutrition causes anaemia, weakness of the body, blurred vision, fainting, and dwindling academic performance (National research council, 2007 and Myles, 1993).

3. Nutritional deficiencies contribute to the high rates of disability, morbidity, and mortality, especially among infants and young children with several data suggesting a crisis in the nutrition situation of the country.

In the short term, poor nutrition can contribute to stress, tiredness, reduced capacity to work, and over time, it can contribute to the risk of developing some illnesses and other health problems such as:

- being overweight or obese

- tooth decay

- $\quad$ high blood pressure 
- $\quad$ high cholesterol

- heart disease and stroke

- type-2 diabetes

- osteoporosis

- $\quad$ some cancers

- depression

- $\quad$ eating disorders.

\section{Strategies to reduce major nutritional problems}

Strategies to reduce major nutritional problems include the following:

1. Continuous Promotion of Exclusive Breastfeeding: Recent research findings have now linked artificial feedings of infants to have great influence on onset of type 2 diabetes mellitus, obesity, and cardiovascular diseases. Exclusive breastfeeding for the first six months have been proven to have the greatest impact in the reduction of non- communicable chronic diseases. The continuous promotion should be continued if infant mortality will be reduced to the expected level by 2020 . The zeal for promotion of breastfeeding among healthcare has been drastically reduced to almost one a year during breastfeeding month of each year. This should not be so.

2. Emphasis on Preventive Care: It has been demonstrated that health system of the world has been more of curative than preventive.

3. Promotion of adequate infant and young child feeding practices should go beyond health information; it should be through practical demonstration in all health facilities.

4. Educate women. The key issue to improve child teaching should include girls, boys, men and women through education that involves both theory and practical demonstrations. Such teachings should include girls, boys, men and women through community involvement activities. The teaching should link between nutrition and childhood and adulthood diseases.

5. Training of community health care providers on current nutrition issues. The training of health care providers not only in the growth monitoring and promotion but they should also be exposed to identification and prevention of non-communicable chronic diseases. There is the dire need for training in nutrition as related to non-communicable chronic diseases such as obesity, type 2 diabetes mellitus, stroke, and hypertension, prostate, colonic and breast cancers.

6. Integrated Approach in PHC: Most of the health programme on PHC have been on vertical line and some of them are 'Top -down' approach with very little local initiative and participation. This should be changed to bottom-up approach with full participation of the community at the initiation of any health programme that will be executed in the community.

7. Nutrition involvement with the Private Sector: Private sector involvement in the prevention of nutritional related diseases is very limited. The private sector should be involved at the community level at all cost.

8. Supplementation and Fortification: Supplementation and fortification are short term interventions that are cost effective especially fortification. Ideally, popularly consumed foodstuffs by the people should be used for fortification programme.

9. Controlling of parasitic infection. Prior to any supplementation of fortified foodstuffs, to infants or pregnant women, deworming is compulsory.

10. Researches in Nutritional Related health problems are needed to document prevention of noncommunicable chronic diseases and lifestyles patterns.

\section{Conclusion}

Nutrition is the science that interprets the interaction of nutrients and other substances in food (e.g phytonutrients, anthocyanin's and tannins etc), in relation to maintenance, growth, reproduction, health and disease of 
an organism. It plays a key role in realization of the "Sustainable Development Goals". We are what we eat; every diet has nutrients that influence our health and the outcome of our health either now or later in life.

\section{References}

Alaimo, K., Olson. C., Frongillo, E., and Briefel, R. (2001). Food insufficiency, family income, and health in US preschool and school-aged children. American Journal of Public Health, 91, 781-786.

Clark, M. and Fox, M., (2009). Nutritional quality of the diets of US public school children and the role of the school meal programs. Supplement to the Journal of the American Dietetic Association, 109, S44 - S56.

Center on Hunger and Poverty. (2002). The consequences of hunger and food insecurity for children: evidence from recent scientific studies. Wallham, MA: Brandeis University.

Center for Disease Control and Prevention, (2010), National Center for Health Statistics. CDC growth charts. Retrieved from www.cdc.gov/growthcharts/

Colby-Morley, E. (1981). Neurotransmitters and nutrition. Orthomolecular Psychiatry, 12, 38-43.

Erikson, J. (2006). Brain food: the real dish on nutrition and brain function. WisKids Journal, November/December.

Finkelstein, D., Hill, E. and Whitaker, R. (2008). School food environments and policies in US public

schools. Pediatrics, 122, 251-259.

Geier, A., Foster, G., Womble, G., McLaughlin, J., Borradaile, K., Nachmani, J. and Schults, J. (2007). The relationship between relative weight and school attendance among elementary schoolchildren. Obesity, $15,2157-2161$.

Growdon, J. H. and Wurtman, R. J. (1980). Contemporary nutrition: nutrients and neurotransmitters. New York State Journal of Medicine.

Halterman, J., Kaczorowski, J., Aligne, C., Auinger, P. and Szilagyi, P. (2001). Iron deficiency and cognitive achievement among school-aged children and adolescents in the United States. Pediatrics, 107,13811386.

Jyoti, D., Frongillo, E., and Jones, S. (2005). Food insecurity affects school children's academic performance, weight gain, and social skills. The Journal of Nutrition, 135, 2831-2839.

Kar, B., Rao, S., and Chandramouli, B. (2008). Cognitive development in children with chronic protein energy malnutrition. Behavioral and Brain Functions, 4:31, doi: 10.1186/1744 9081-4-31.

Kleinman, R., Hall, S., Green, H., Korzec-Ramirez, D., Patton, K., Pagano, M., and \& Murphy, J. (2002). Diet, breakfast, and academic performance in children. Annals of Nutrition \& Metabolism, 46, 24-30.

Kubik, M., Lytle, L., Hannan, P., Perry, C., \& Story, M. (2003). The association of the school food environment with dietary behaviors of young adolescents. American Journal of Public Health, 93, 1168-1173.

Lahey, M., Rosen, S. (2002). Dietary factors affection learning behavior. Retrieved from http://childrensdisabilities.info

Li, Y., DaL Q., Jackson J., and Zhang, J. (2008) Overweight is associated with decreased cognitive function among school-age children and adolescents. Obesity, 16, $1809-1815$.

Meyer. M_ (2005). Upper-elementary students' perception of school meals. The Journal of Child Nutrition \& Management, issue 1, spring.

Neumark-Sztainer, D., French, S., Hannan, P., Story, M., and Fulkerson, J. (2005). School lunch and snacking patterns among high school students: associations with school food

Environment and policies. International Journal of Behavioral Nutrition and Physical Activity, 2:14, doi: 10.11864/1479-5868-2-14.

Ratcliffe, M., Merrigan, K., Rogers, B., and Goldberg, J. (2009). The effects of school garden experiences on middle school-aged students' knowledge, attitudes, and behaviors associated with vegetable consumption. Health Promotion Practice, Society for Public Health Education, doi: 10.1177/1524839909349182.

Sampson, A., Dixit, S., Meyers, A. and Houser, R, (1995). The nutritional impact of breakfast consumption on the diets of inner-city african-american elementary school children. Journal of the National Medical Association, 87, 195-202.

Shore, S., Sachs, M., Lidicker, J., Brett, S., Wright, A,, \& Libonati, J. (2008). Decreased scholastic achievement in overweight middle school students. Obesity, 16, 1535-1538.

Winchell, M. (2009). Eating Democracy and Corn Puppies. Reviews in American History, 37, 117-124, doi: 10.1353/rah.0.0076

Wolfe, P., Burkman, A., \& Streng, K. (2000). The science of nutrition. Educational Leadership March.

Wolpert S., and Wheeler, M. (2008). Food as brain medicine. UCLA Magazine Online, Retrieved http://magazine.ucla.edu

Wood, M. (2001). Studies probe role of minerals in brain function. Agriculture Research, 49.10.

Zhang, J., Hebert, J., and Muldoon, M. (2005). Dietary fat intake is associated with psychosocial and cognitive 
functioning of school-aged children in the United States. The Journal of Nutrition, 35, 1967-1973.

American College of Sports Medicine Position Stand (1998). The recommended quantity and quality of exercise for developing and maintaining cardiorespiratory and muscular fitness, and flexibility in healthy adults.Metl Sci Sports Exerc; 30: 975-91.

Booth SL, Broe KE, Gagnon DR, (2013) et al. Vitamin K intake and bone mineral density in women and men. Am J Clin Nutr 2003; 77: 512-6.

Centre for Nutrition Policy and Promotion (1995). The healthy eating index. Washington, DC: US Department of Agriculture,

Fukui K, Onodera K., Shinkai T., Suzuki S., Urano S. (2001) Impairrnent of learning and memory in rats caused by oxidative stress and aging, and changes in ant oxidative defense systems. Ann N Y Acad Sci 928: 16875 . 